\title{
Pathogenicity and Distribution of Fusarium solani Isolates Associated with Erythrina Decline in Japan
}

\author{
Kuya Takashina, ${ }^{1, \dagger}$ Izumi Chuma, ${ }^{2}$ Hisashi Kajimura, ${ }^{3}$ Norikazu Kameyama, ${ }^{4}$ Chiaki Goto,${ }^{5}$ and Keiko Kuroda ${ }^{1, \dagger}$ \\ ${ }^{1}$ Graduate School of Agricultural Science, Kobe University, Kobe, 657-8501, Japan \\ ${ }^{2}$ Obihiro University of Agriculture and Veterinary Medicine, Obihiro, 080-8555, Japan \\ ${ }^{3}$ Graduate School of Bioagricultural Sciences, Nagoya University, Nagoya, 464-8601, Japan \\ ${ }^{4}$ Faculty of Agriculture, University of the Ryukyus, Okinawa, 903-0213, Japan \\ ${ }^{5}$ Faculty of Agriculture, Kobe University, Kobe, 657-8501, Japan
}

\begin{abstract}
Erythrina spp. trees have been declining since the 2000s worldwide, and fungi belonging to Fusarium solani species complex (FSSC) have been suggested to be a causal factor of decline and mortality of Erythrina variegata trees in Okinawa Island, Japan. In addition to the FSSC isolate grouped as "it-1" based on ITS sequence data (previously called strain A), we conducted an inoculation experiment with two isolates grouped as "it-2" (previously strain B), which is genetically close to it-1. Two it-2 isolates originating from two islands showed pathogenicity to $E$. variegata with the same symptoms as those caused by it-1 isolate. We also found the isolates of it- 1 and it- 2 were widely distributed, including on Ishigaki Island, $400 \mathrm{~km}$ south of Okinawa Island across the ocean.

All isolates of it- 1 and it- 2 belong to the ambrosia Fusarium clade of the FSSC, a group of symbionts of ambrosia beetles, including the pathogens of Fusarium dieback in avocados and teas. The detection of ambrosia beetles Euwallacea spp. from our specimens provided information on the vectors of the pathogens. Our present results suggest the fungi of the FSSC could be responsible for the Erythrina decline in other areas with damage.

Keywords: Erythrina variegata, wilt disease, Quadrastichus erythrinae, Fusarium solani species complex, ambrosia Fusarium, ambrosia beetle
\end{abstract}

The decline and mortality of coral trees (Erythrina spp.) have been increasing since the 2000s in a wide area of tropical and subtropical regions of Asia, Hawaii, and a few regions on the American continent (Uechi et al. 2007). Erythrina trees are designated in agroforestry as shade trees for pepper, cacao, and coffee and as ornamental trees in parks (Kumar et al. 2010). Erythrina variegata, the Indian coral tree, which is widely planted in the southern islands of Japan, has also shown decline and mortality since the 2000s. Although an infestation by the gall wasp Quadrastichus erythrinae has been believed to be the cause of the decline, based on the observation that many galls are found on the leaves of declining trees (Kim et al. 2004; Rubinoff et al. 2010; Uechi et al. 2007), there was no scientific data on the causal relationship between the gall wasp infestation and the decline and mortality of Erythrina trees. It is well known that the injection of insecticides in the trunks of Erythrina trees does not always effectively prevent decline. In Hawaii, biological control with a parasitic wasp from Africa was recently conducted to protect an indigenous Erythrina species (Messing et al. 2008; Reimar 2008). However, Yalemar et al. (2009) reported that this method did not always have positive effects.

For this reason, the authors thought that the real causal factor of the decline and mortality should be found in order to protect Erythrina trees, and we focused on the pathological incidences in trees at various stages of decline before death. Kuroda et al. (2017) found that specific fungi are distributed consistently in the discolored xylem of declining trees. In addition, anatomical observation proved that

${ }^{\dagger}$ Corresponding authors: K. Takashina; soranari54@gmail.com and K. Kuroda; kurodak@garnet.kobe-u.ac.jp

Funding: This work was supported by Japan Society for the Promotion of Science KAKENHI Grant Numbers JP15K14747 and JP17H03831 and by Okinawa Prefecture Budget Division.

The author(s) declare no conflict of interest.

Accepted for publication 5 October 2019.

C 2020 The American Phytopathological Society those trees died of water deficit due to the blockage of water conduction in the discolored xylem in which Fusarium spp. were distributed. These results suggested that the occurrences might be results of wilt disease caused by fungi. From the DNA sequencing of the rDNA-ITS gene repeat, the fungi most frequently detected in declining trees were revealed to belong to the Fusarium solani species complex (FSSC) (recently reported as Neocosmospora [Lombard et al. 2015]). The detected isolates were grouped on the basis of the similarity in the base sequences, and two groups of them, which include many isolates from various specimens, were named strain $\mathrm{A}$ and strain B in the previous report (Kuroda et al. 2017). Those groupings were renamed as it-1 (strain A) and it-2 (strain B) in the present report. The artificial inoculation of healthy seedlings with an isolate of it-1 was conducted to check the pathogenicity, and it showed the same symptoms as naturally declining trees of E. variegata on Okinawa Island, that is, an abnormal defoliation associated with decreased water uptake, necrosis of the cambium and phloem with an odor, and, finally, the death of the whole tree. By the successful reisolation of the inoculated fungus from dead seedlings, Kuroda et al. (2017) concluded that an isolate-P2-f11 of it-1 obtained from Okinawa Island-is pathogenic to E. variegata and that E. variegata is dying from a new disease caused by a fungus in the it- 1 group belonging to the FSSC.

The next steps were to check the pathogenicity of other isolates belonging to the group it- 2 of the FSSC. In addition, surveillance was necessary on the geographical distributions of the FSSC pathogenic to $E$. variegata to find areas affected by the pathogens and to reveal the routes of infection from diseased to healthy trees. Therefore, the aims of this research are (i) to add fundamental information of geographic distribution of FSSC associated with declining Erythrina trees and (ii) to check the pathogenicity of the isolate group it-2 in addition to it-1 (Kuroda et al. 2017). In the preceding investigation, isolates phylogenetically the same as it- 1 and it- 2 were both detected at two sites $17 \mathrm{~km}$ apart on Okinawa Island (Kuroda et al. 2017). This suggested that pathogenic fungi might be distributed in a wide area, even beyond Okinawa Island or Japan. Confirmation of the universal detection of the pathogenic fungus in all declining E. variegata is essential to find strategies to protect this tree species. For that purpose, geographical surveillance of the FSSC associated with Erythrina 
decline was expanded to Ishigaki Island, $400 \mathrm{~km}$ from Okinawa Island. In addition, geographical differences in pathogenicity were compared by an artificial inoculation experiment using two it-2 isolates that were detected at different sites. If Erythrina mortality in tropical Asian countries, the American continent, and Hawaii is also caused by similar fungi or closely related to our pathogenic isolates of the FSSC, the present information will be helpful in those areas.

\section{Materials and Methods}

Surveying of declining trees and sampling. E. variegata trees planted as ornamental or shade trees were surveyed on Ishigaki and Okinawa Islands, Okinawa Prefecture, Japan, in 2017. Specimens were taken from declining trees, as indicated in Table 1 . The level of decline in trees was evaluated based on the method used in Kuroda et al. (2017) as follows: level 1 trees are extensively damaged with sparse leaves; level 2 trees are moderately damaged but still have abundant leaves; and level 3 trees appear healthy, although they have infestations of $Q$. erythrinae.

Two declining trees, Is1 and Is2, were selected from a private garden in Ibaruma, Ishigaki City, Ishigaki Island. Tree Is 1 had abundant leaves, although it was abnormally defoliated and had galls of $Q$. erythrinae (level 2, moderate damage). Tree Is2 had few leaves and was judged to be close to death (level 1, extensive damage). On Okinawa Island, two roadside trees, On1 and On2, with sparse leaves (level 1) were selected at Nakama, Onna-son Village, Kunigami-gun. In addition, one tree, R10, with abundant leaves with galls of $Q$. erythrinae (level 2) was selected at the University of the Ryukyus, Nishihara-cho, Nakagami-gun. From the selected trees, declining branches were cut or wood blocks with necrotic tissue were cut from the stems and were processed for further observation and the detection of fungi in the laboratory. In the preceding investigation (Kuroda et al. 2017), we found that it is difficult to judge whether Erythrina trees are infected or healthy because most of the Erythrina trees in Okinawa Prefecture have been infested by $Q$. erythrinae and subsequently have lost some leaves or young shoots. In addition, owners, including the local government, did not permit us to cut down apparently healthy ornamental or roadside trees. Therefore, we used tissues without necrosis and discoloration from slightly affected trees as a kind of control for comparing fungal distribution.
Sampling and identification of beetles. Trunks and branches of declining trees were checked for pinholes and galleries of ambrosia beetles on the surface, or, after harvest, galleries in the xylem of trunks and branches were checked for galleries by splitting specimens with a chisel. When adult beetles were found inside the tissue, they were collected and identified under a binocular microscope based on their morphology.

Macroscopic observation and the procedure of fungal isolation. Harvested branches or stem blocks were cut into smaller pieces and observed with a stereoscopic microscope (SMZ1500, Nikon, Tokyo, Japan), and the cut surfaces were photographed with a digital camera. First, the macroscopic conditions of the phloem and xylem of slightly damaged trees (level 2) were compared with those of severely damaged trees (level 1), and abnormal areas, including discolored xylem and necrotic phloem, were processed for the detection of fungi as follows.

Each specimen (Table 1, Is1 to R10) was dissected into small blocks $(5 \times 5 \times 5 \mathrm{~mm})$ with disposable knife blades. These blocks were washed with $70 \%$ ethanol, and the surfaces were sterilized with aqueous sodium hypochlorite (effective chlorine concentration $0.5 \%$ ). The blocks were placed on potato dextrose agar (PDA) in 9-cm Petri dishes and incubated at $25^{\circ} \mathrm{C}$. Another block $(2 \times 3 \times$ $3 \mathrm{~cm}$ ) of each sample block was kept in a sterilized empty Petri dish. After 5 days, hyphae emerging from the blocks were directly picked with a lancet and incubated on PDA as described above.

Isolate identification and phylogenetic analysis. For the phylogenetic analysis of isolates, DNA sequencings of the rDNA-ITS gene repeat and the translation elongation factor $(E F-1 \alpha)$ gene were conducted as follows. Mycelial cultures grown on PDA were suspended in $100 \mu \mathrm{l}$ of Tris-EDTA buffer, incubated at $95^{\circ} \mathrm{C}$ for $10 \mathrm{~min}$, and used as a PCR template. The rDNA-ITS was amplified with primers ITS5 (5'-GGAAGTAAAAGTCGTAACAAGG-3') and ITS4 (5' TCCTCCGCTTATTGATATGC-3') (White et al. 1990), and $E F$ $1 \alpha$ was amplified with primers EF-1H (5'-ATGGGTAAGGAAGA CAAGAC-3') and EF-2T (5'-GGAAGTACCAGTGATCATGTT$\left.3^{\prime}\right)$ (O'Donnell 2000) in a 20- $\mu$ l reaction of KOD FX Neo DNA polymerase (TOYOBO, Osaka, Japan).

DNA sequencing was conducted using ABI PRISM 3100 and 3130xl Genetic Analyzer (Thermo Fisher Scientific, U.S.A.) at the Biosignal Research Center, Kobe University, including all of the

Table 1. Condition of sampled specimens from declining Erythrina variegata

\begin{tabular}{|c|c|c|c|c|c|}
\hline Sampling date & Tree no. & Sampling site & $\begin{array}{c}\text { Tree } \\
\text { height }(\mathrm{m})\end{array}$ & $\begin{array}{c}\text { Leaf quantity } \\
\text { level }^{\mathbf{a}}\end{array}$ & Condition of sampled parts \\
\hline \multirow[t]{2}{*}{ June 21, 2017} & Is1 & A private garden Ibaruma, Ishigaki City & 8 & 2 & Non-discolored xylem \\
\hline & Is 2 & & 10 & 1 & $\begin{array}{l}\text { Base of a branch with discolored xylem and } \\
\text { necrotic phloem }\end{array}$ \\
\hline \multirow[t]{2}{*}{ June 22, 2017} & On1 & $\begin{array}{l}\text { Roadside at Nakama, Onna-son Village, } \\
\text { Kunigami-gun }\end{array}$ & 5 & 1 & $\begin{array}{l}\text { Base of two branches with discolored xylem } \\
\text { and necrotic phloem }\end{array}$ \\
\hline & On2 & & 4 & 1 & $\begin{array}{l}\text { Base of the trunk with discolored xylem and } \\
\text { necrotic phloem }\end{array}$ \\
\hline June 23, 2017 & R10 & $\begin{array}{l}\text { Univ. of the Ryukyus Nishihara-cho, } \\
\text { Nakagami-gun }\end{array}$ & 7 & 2 & $\begin{array}{l}\text { Base of branch with discolored xylem and } \\
\text { necrotic phloem }\end{array}$ \\
\hline
\end{tabular}

${ }^{\text {a }}$ Level 1 = small quantity of leaves; level 2 = abundant leaves; and level 3 = healthy condition.

Table 2. Inoculation of healthy Erythrina variegata seedlings with two isolates of it-2 of the Fusarium solani species complex from two sites on Okinawa and Ishigaki Islands

\begin{tabular}{|c|c|c|c|c|c|c|c|}
\hline \multirow[b]{2}{*}{ Treatment } & \multirow[b]{2}{*}{ Specimen no. } & \multirow{2}{*}{$\begin{array}{l}\text { Number of } \\
\text { seedlings }\end{array}$} & \multicolumn{2}{|r|}{ Inoculum (it-2) } & \multirow[b]{2}{*}{ Height (cm) } & \multirow[b]{2}{*}{ Diameter (mm) } & \multirow[b]{2}{*}{ Number of leaves } \\
\hline & & & Isolate name & Detected site & & & \\
\hline \multirow[t]{2}{*}{ Inoculation } & Ru-ino $1-24$ & 24 & $\mathrm{R} 1-\mathrm{BC}^{\mathrm{a}}$ & Univ. of the Ryukyus, Okinawa Island & $23-51$ & $7.6-14.9$ & $18-37$ \\
\hline & Is-ino $1-24$ & 24 & Is $2-\mathrm{f}^{\mathrm{b}}$ & Private garden, Ishigaki Island & $24-52$ & $7.4-15.9$ & $13-39$ \\
\hline \multirow[t]{2}{*}{ Control } & WCt $1-6$ & 6 & $c^{c}$ & & $25-52$ & $7.1-13.0$ & $12-29$ \\
\hline & $\mathrm{NCt} 1-6$ & 6 & $-^{c}$ & & $21-33$ & $6.5-10.6$ & $20-26$ \\
\hline
\end{tabular}

a Detected from the specimen R1 sampled on May 20, 2014 (Kuroda et al. 2017).

$\mathrm{b}$ Detected from the specimen Is2 sampled on June 21, 2017.

${ }^{\mathrm{c}}$ Without fungus inoculation on the wounded control (WCt 1-6) and nonwounded control (NCt 1-6). 
isolates for comparison with the previously obtained data of strains A and B, it-1 and it-2 (Kuroda et al. 2017). Nucleotide sequences were aligned with the program ClustalW and manually optimized using the program MEGA version 7 (Kumar et al. 2016). Isolates not belonging to the FSSC were identified to the genera level by using the ITS gene sequence as a BLAST query. DNA sequencing of the $E F-1 \alpha$ was conducted for the phylogenetic analysis of selected isolates that showed sequence data that were the same as or close to those of it- 1 and it-2. We used the sequence data of $F$. staphyleae and 31 FSSC isolates reported by Aoki et al. (2018), Costa et al. (2016), Kasson et al. (2013), O'Donnell et al. (2008, 2015), and Zhang et al. (2006), which were obtained from GenBank for multiple sequence alignment using ClustalW and analysis by MEGA version 7. The phylogenetic relationship was inferred using the maximum likelihood method based on the Jukes-Cantor model (Jukes and Cantor 1969). All positions containing gaps and missing data were eliminated. Nodal supports were assessed via 1,000 bootstrap replicates. F. staphyleae was used as an outgroup species in the dendrogram.

Microscopic observation of declining trees. Specimens were processed by light microscopy to observe the distribution of fungal hyphae and the effects of infection. Specimens were cut into small blocks $(1 \times 1 \times 2$ to $2 \times 2 \times 3 \mathrm{~cm})$ and fixed in formalin, acetic acid, and 50\% ethyl alcohol (FAA, 5:5:90, v/v) for 1 week. They were subsequently washed for 1 day under tap water. With a sliding microtome (Ritratome REM-710, Yamato Koki Co., Asaka, Saitama, Japan), sections (transverse, tangential, and radial) 20 to $30 \mu \mathrm{m}$ thick were cut from the tissue blocks. Some of the sections were stained with periodic acid-Schiff to stain polysaccharides and toluidine blue O to stain fungal hyphae (Feder and O'Brien 1968). A part of each section was mounted onto a glass slide without staining to observe the natural colors and cytological changes. Microscopic observation (ECLIPSE 80i, ECLIPSE Ni-U, Nikon) was focused on the distribution of fungal hyphae and was compared with those of the previous study by Kuroda et al. (2017).

Inoculation experiment. Sixty 1-year-old E. variegata seedlings (height, 21 to $52 \mathrm{~cm}$; diameter, 6.5 to $15.9 \mathrm{~mm}$; number of leaves, 12 to 39 ) were provided by Ryukyu Sankei Co. in Okinawa Prefecture and were used in the inoculation experiment (Table 2). Two isolates-R1-BC6, detected on Okinawa Island in 2014 (Kuroda et al. 2017), and Is2-f4, detected on Ishigaki Island in 2017-were used as inocula. These isolates both belong to the FSSC and, based on

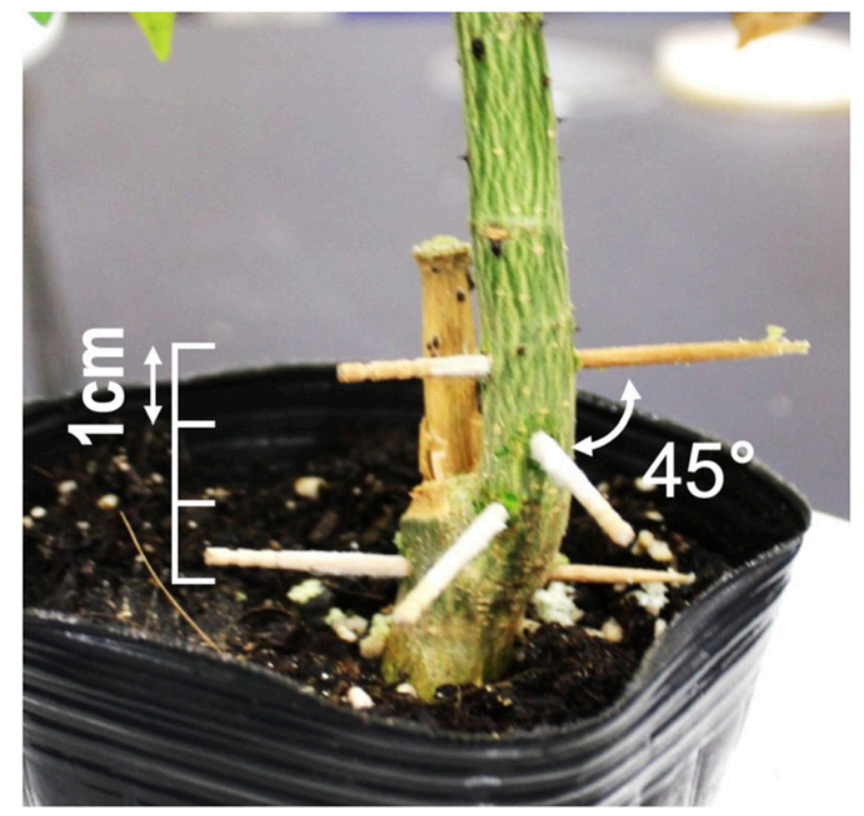

Fig. 1. Inoculation of healthy Erythrina variegata seedlings with toothpicks with mycelia of the it-2 isolates. Four toothpicks were used to pierce the stem $1.5 \mathrm{~cm}$ above the ground and at $1-\mathrm{cm}$ intervals upward, shifting $45^{\circ}$ between each hole. the coincidence of the rDNA-ITS data with primers ITS5 and ITS4, were categorized as it-2. The inocula were cultured on toothpicks placed on PDA in 9-cm Petri dishes at $25^{\circ} \mathrm{C}$ for 2 weeks. Inoculation was conducted on the lower stems of 48 seedlings on July 31 ,

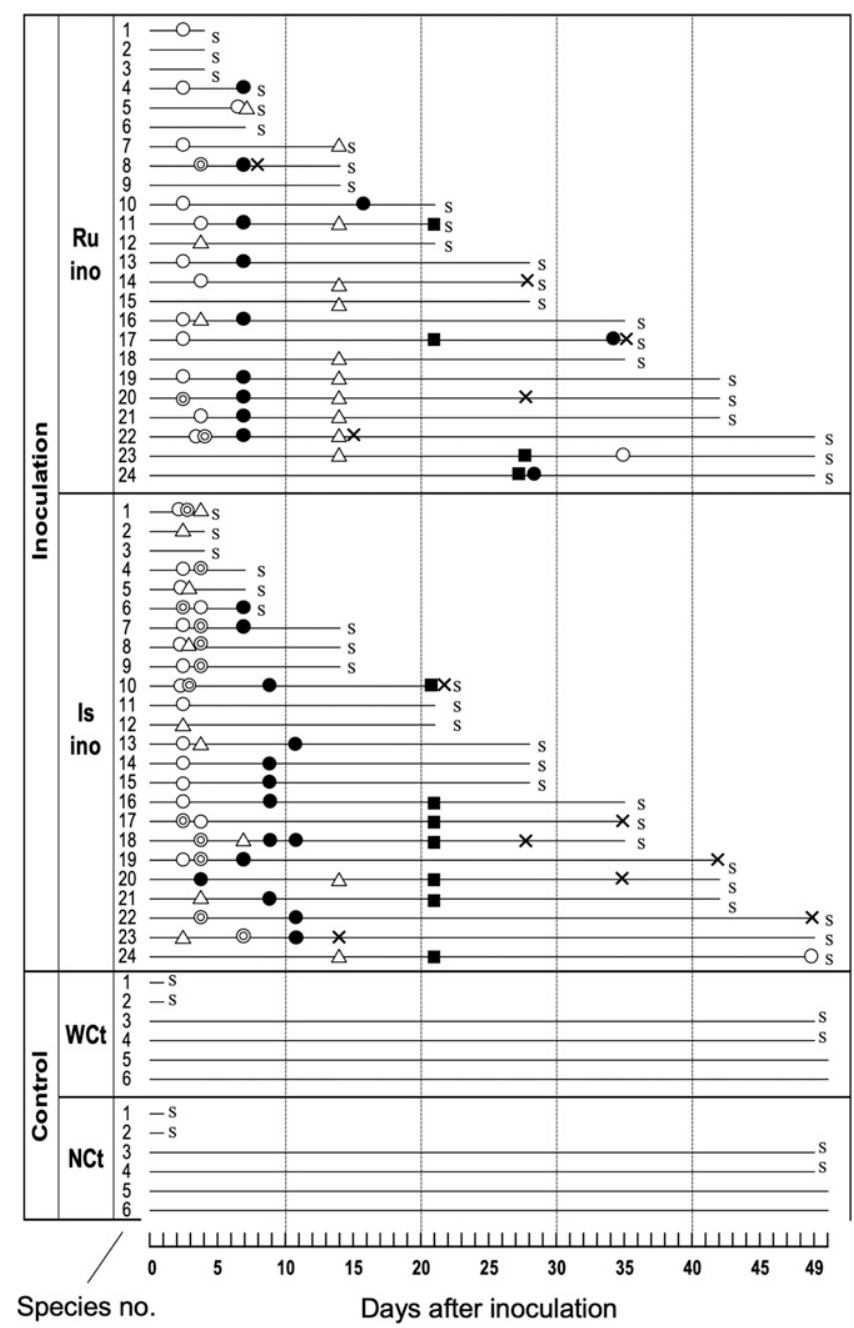

Fig. 2. Development of external symptoms in Erythrina variegata seedlings for 49 days after the inoculation date. Seedlings numbered 1 to 24 in the sections labeled Ru-ino and Is-ino were those inoculated with the isolate R1-BC6 detected on Okinawa Island or Is2-f4 detected on Ishigaki Island, respectively (Table 2). WCt = control specimens inoculated with sterilized toothpicks; $\mathrm{NCt}=$ no-wound control specimens; $\mathrm{S}=$ sampling date; $\bigcirc$ = leaf drooping; $\odot$ = leaf wilting; $\bullet$ = complete defoliation; $\triangle$ = fluid exudation; = necrosis of cortex and phloem; and $\mathrm{x}=$ death.

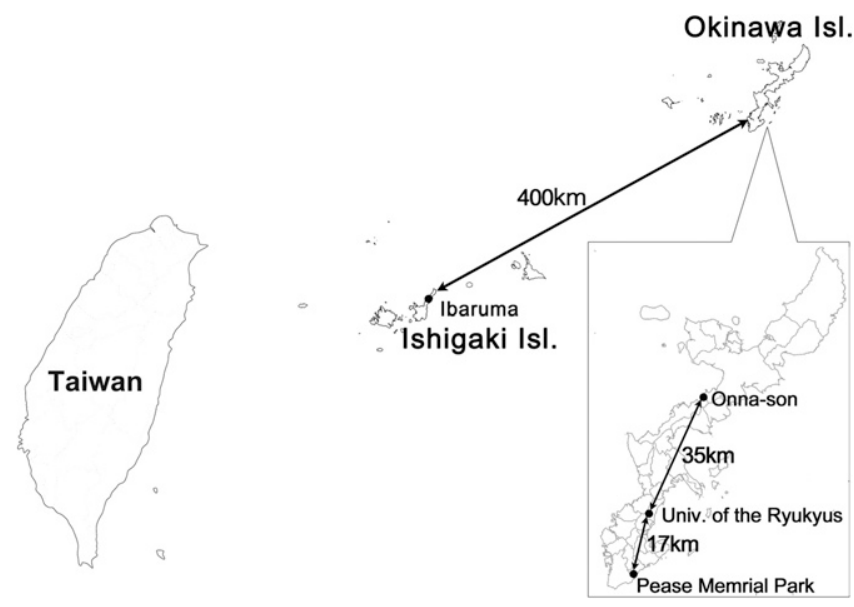

Fig. 3. Sampling sites of Erythrina variegata specimens and distances between sites. 
2017, following the method of Morita et al. (2016) and Sumida et al. (2016). Before the inoculation, four holes were drilled, piercing each stem of E. variegata seedlings at $1.5 \mathrm{~cm}$ above the ground and at $1-\mathrm{cm}$ intervals upward from the lowest hole, shifting $45^{\circ}$ horizontally between each hole (Fig. 1). Then, toothpicks with mycelia were inserted into the four holes. The inoculated sites were covered with Parafilm. Twenty-four seedlings were inoculated with R1-BC6, and the others were inoculated with Is2-f4. As a control without fungus, sterilized toothpicks were inserted into six seedlings. Healthy seedlings were also used as no-wound control specimens (Table 2). The inoculated and control seedlings were placed on the two adjacent balconies under the roof at a 1-m distance separated by a mesh partition at Kobe University. Control specimens were put $\sim 5 \mathrm{~m}$ from inoculated seedlings. All seedlings were watered once a day. During this experiment period, from July 31 to September 18, 2017, the temperature was as high as $34.1^{\circ} \mathrm{C}$ and as low as $22.0^{\circ} \mathrm{C}$.

After the inoculation, external symptoms, such as leaf drooping and defoliation, were monitored every day. The death of specimens was determined by complete defoliation and the death of cambial cells and apical meristems. Seedlings were harvested from each inoculated group on the fourth day and at 7-day intervals thereafter (Table 2, Fig. 2). Two control seedlings were harvested on

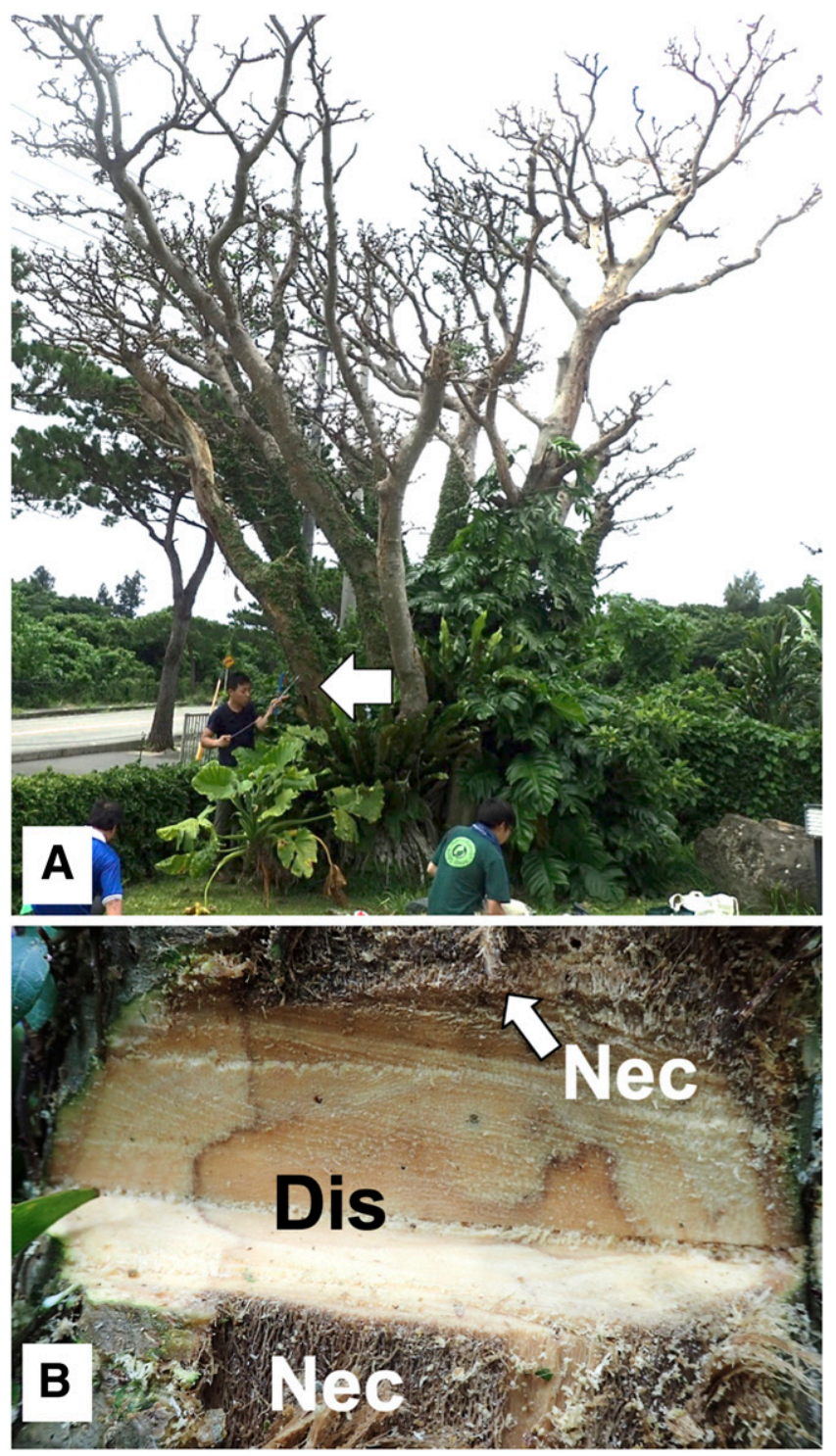

Fig. 4. A heavily damaged Erythrina variegata tree harvested at Ibaruma, Ishigaki Island, on June 21, 2017. A, Tree Is2 with dead branches; arrow points to the sampled part. B, Xylem discoloration (Dis), phloem, and cambium necrosis (Nec) occurring in the trunk of Is2.
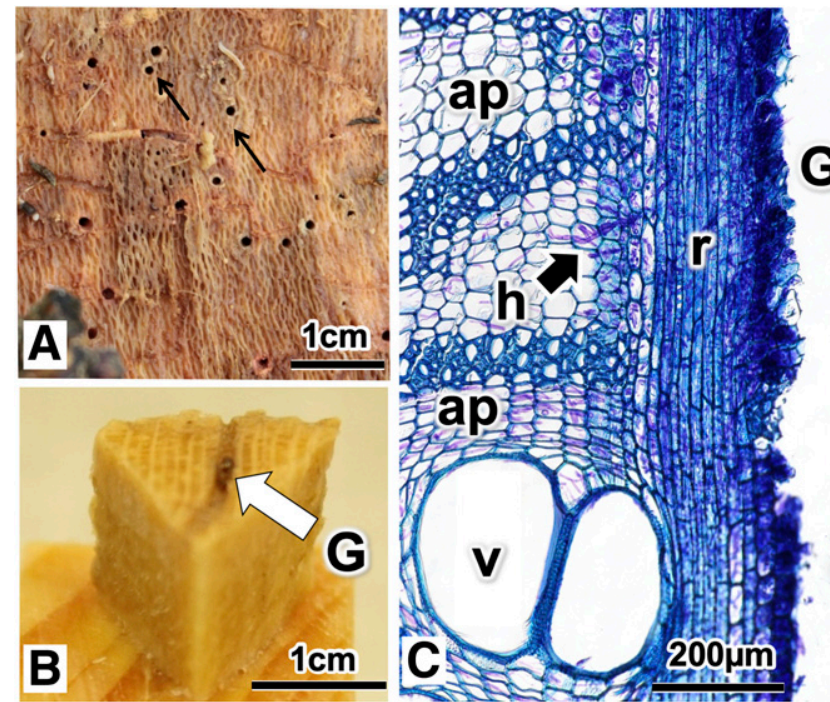

Fig. 5. Galleries of ambrosia beetle Euwallacea spp. found in a declining Erythrina variegata tree at University of the Ryukyus. A, Galleries (arrows) at the exfoliated bark of a dead branch. B, Discolored xylem around a gallery $(G)$ in a dead branch. C, A cross-sectional microphoto along a beetle gallery (G). Hyphae (arrow $h$ ) are elongating from the gallery $(G)$ through vessels $(v)$ and ray tissue $(r)$ and invading into axial parenchyma cells (ap) adjacent to vessels. Stained with toluidine blue 0.

\section{$400 \mu \mathrm{m}$}

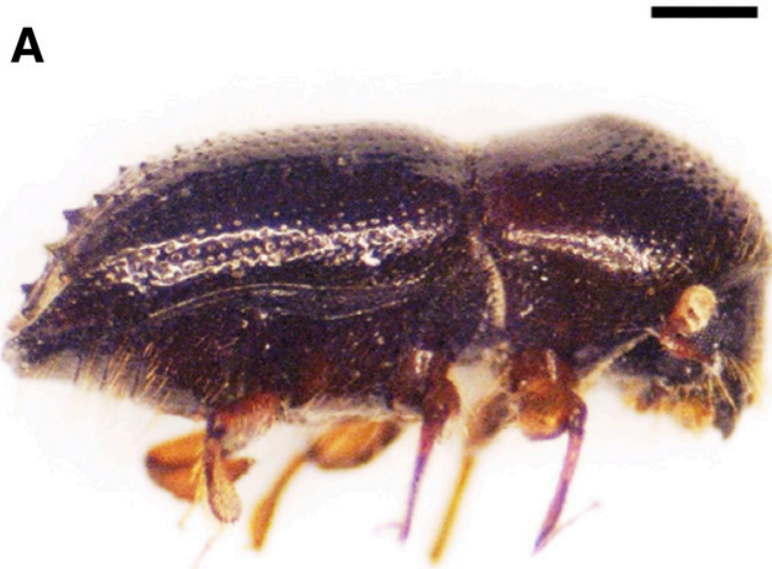

B
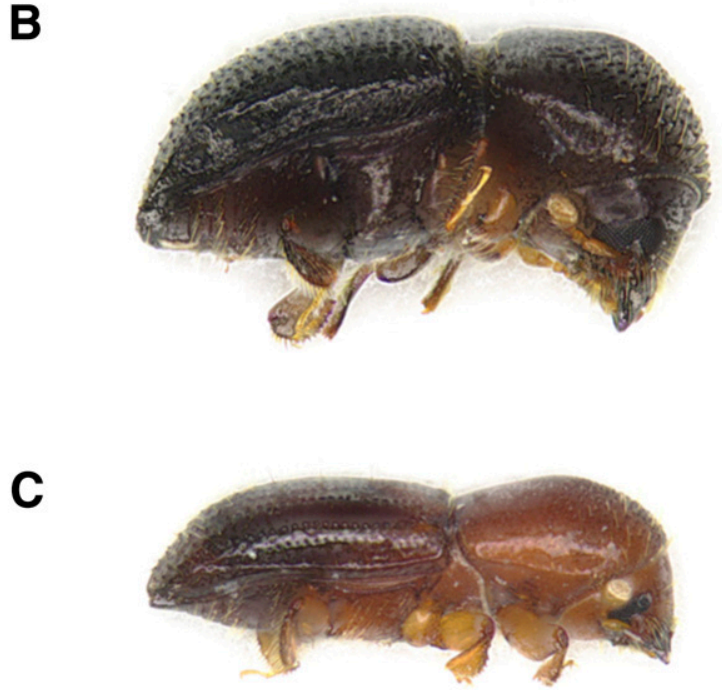

Fig. 6. Lateral views of A, Euwallacea funereus, B, E. fornicatus, and C, E. piceus detected in declining Erythrina variegata trees in Ishigaki $(A)$ and Okinawa $(B, C)$ Islands. 
inoculation day and 49 days later. Internal symptoms were then observed using anatomical techniques. The harvested stems were cut at heights of 3,13 , and $23 \mathrm{~cm}$ from the base. The cut surfaces were observed with a stereoscopic microscope. Specimen blocks $(1 \times 1 \times$ $2 \mathrm{~cm}$ ) were then taken from the adjacent areas, fixed in FAA, and processed for light microscopy, as in the case of naturally infected trees. The distribution of hyphae in the tissues and the response of host cells to the fungal infection were examined by light microscopy. Tissues of control specimens were compared with those of fungusinoculated seedlings. Reisolation of the inoculated fungi was conducted with the same method of fungal isolation from naturally infected trees. Tissue blocks $(5 \times 5 \times 5 \mathrm{~mm})$ were cut from harvested seedlings and incubated in PDA. DNA sequencing of the rDNA-ITS gene repeat was conducted to check whether reisolated fungi have the same nucleotide sequences as the FSSC it-2 isolates, R1-BC6 and Is $2-\mathrm{f} 4$ of it- 2 .

\section{Results}

Macroscopic and microscopic characteristics of declining trees. The decline and mortality of E. variegata were also serious on Ishigaki Island $400 \mathrm{~km}$ south of Okinawa Island across the ocean
(Fig. 3). In Ibaruma, northern Ishigaki Island, galls of Q. erythrinae were frequently found on leaves and petioles. Leaves were lost resulting in defoliation of many E. variegata trees. In the Onna-son Village, central Okinawa Island, gall formation was also abundant, and the leaves were abnormally reduced on many E. variegata trees planted along the road. The conditions of the trees harvested from Ishigaki and Okinawa Islands in 2017 are shown in Table 1. In the trunks or branches of heavily damaged and defoliated trees harvested from Ibaruma, Ishigaki Island (specimen Is2) and from Onna-son, Okinawa Island (specimens On1 and On2) (level 1, Table 1; Fig. 4A), pale gray discolored xylem was observed with the naked eye (Fig. 4B, Dis). Although specimen R10 from the University of the Ryukyus had abundant leaves (level 2, Table 1), a thick branch was dead, and grayish discoloration was found on the crosscut surface of the branch. The bark of the trunks and the branches surrounding the discolored xylem was soft and oozed liquid when pressed with the fingertips. Necrosis of the phloem and cambium (Fig. 4B, $\mathrm{Nec}$ ) had occurred in the wide area adjacent to the discolored xylem. A putrid smell was detected from the necrotic and softened tissue. The bark of such necrotic parts was exfoliated easily from the trunk surface. In specimen Is1 from Ishigaki Island, which had abundant

Table 3. Tissue condition in declining Erythrina variegata trees and dominantly detected fungi

\begin{tabular}{|c|c|c|c|c|c|c|c|}
\hline $\begin{array}{l}\text { Tree } \\
\text { no. }\end{array}$ & Sampled part & Cultured part & $\begin{array}{c}\text { Number } \\
\text { of } \\
\text { cultured } \\
\text { pieces }\end{array}$ & $\begin{array}{c}\text { Number } \\
\text { of } \\
\text { isolates }\end{array}$ & Isolate names $^{\mathbf{a}}$ & $\begin{array}{c}\text { FSSC }^{\mathbf{b}} \\
\text { isolate } \\
\text { named by } \\
\text { rDNA-ITS } \\
\text { allele }\end{array}$ & Other isolated fungic \\
\hline \multirow[t]{2}{*}{ Is 1} & Trunk & Non-discolored xylem & 10 & 4 & Is1-b5 & it-2 & Scedosporium sp. \\
\hline & & & & & Is1-b1 & it-3 & Curvularia sp. \\
\hline \multirow[t]{8}{*}{ Is 2} & Base of a branch & Discolored xylem & 28 & 25 & Is2-f2, Is2-g6, Is2-g8 & it-1 & Scedosporium sp. \\
\hline & & & & & $\begin{array}{l}\text { Is2-f4, Is2-f6, Is2-g2, Is2-g7, Is2-g9 } \\
\text { Is2-g10, Is2-h3 }\end{array}$ & it-2 & $\begin{array}{l}\text { Peniophora sp. } \\
\text { Arthrobotrys sp. }\end{array}$ \\
\hline & & & & & Is2-g11 & it-3 & Peniophora sp. \\
\hline & & & & & $\begin{array}{l}\text { Is2-g3, Is2-g5, Is2-g13, Is2-g14 } \\
\text { Ig2-g15, Is2-h2 }\end{array}$ & it-4 & Geotrichum sp. \\
\hline & & Discolored xylem & 25 & 13 & Is2-a2, Is2-b3 & it-3 & Scedosporium sp. \\
\hline & & & & & Is2-e1, Is2-e3, Is2-e6, Is2-e7 & it-4 & Pythiogeton sp. \\
\hline & & & & & Is $2-\mathrm{f} 8$ & & $\begin{array}{l}\text { Arthrinium sp. } \\
\text { Hypocrea sp. } \\
\text { Ceriporia sp. }\end{array}$ \\
\hline & & Exfoliated bark & 7 & 4 & Is2-c2, Is2-c3 & it-1 & $\begin{array}{l}\text { Botryosphaeria sp. } \\
\text { Penicillium sp. }\end{array}$ \\
\hline \multirow[t]{14}{*}{ On1 } & Top of a branch & Discolored xylem & 21 & 20 & $\begin{array}{l}\text { On1-c1, On1-c2, On1-c3, On1-c4 } \\
\text { On1-c8, On1-c9, On1-c11, On1-c13 } \\
\text { On1-c18 }\end{array}$ & it-1 & Paracremonium sp. \\
\hline & & & & & On1-c5, On1-c6, On1-c7, On1-c10 & it-3 & \\
\hline & & & & & On1-c12, On1-c14, On1-c15, On1-c16 & & \\
\hline & & & & & On1-c19, On1-c20 & & \\
\hline & Base of a branch & Discolored xylem & 51 & 43 & On1-a1, On1-a8, On1-b2, On1-b9 & it-1 & Ceriporia sp. \\
\hline & & & & & On1-b1, On1-b5, On1-b7, On1-b8 & it-2 & Lasiodiplodia sp. \\
\hline & & & & & On1-b11, On1-b13, On1-b14, On1-b15 & & \\
\hline & & & & & On1-b16, On1-b20, On1-b21, On1-b22 & & \\
\hline & & & & & On1-b23, On1-b24, On1-b25 & & \\
\hline & & & & & On1-a2, On1-a3, On1-a4, On1-a5 & it-3 & \\
\hline & & & & & On1-a6, On1-a7, On1-a10, On1-a12 & & \\
\hline & & & & & On1-a13, On1-a14, On1-a15, On1-a16 & & \\
\hline & & & & & On1-a17, On1-a20, On1-a21, On1-a22 & & \\
\hline & & & & & On1-a23, On1-a24, On1-a25, On1-a26 & & \\
\hline \multirow[t]{3}{*}{ On2 } & Basal trunk & Discolored xylem & 20 & 17 & On2-a5, On2-a6, On2-b2, On2-b3 & it-1 & Lasiodiplodia sp. \\
\hline & & & & & $\begin{array}{l}\text { On2-a3, On2-a4, On2-a7, On2-c2 } \\
\text { On2-c3 }\end{array}$ & it-2 & Pichia sp. \\
\hline & & & & & On2-a1, On2-a2 & it-3 & Paracremonium sp. \\
\hline \multirow[t]{3}{*}{ R10 } & Base of a branch & Discolored xylem & 15 & 12 & R10-a12 & it-1 & Nectriaceae sp. \\
\hline & & & & & R10-a1, R10-a2, R10-a7, R10-a9 & it-2 & \\
\hline & & & & & R10-a11 & & \\
\hline
\end{tabular}

\footnotetext{
a The isolates named by authors.

${ }^{\mathrm{b}}$ FSSC $=$ Fusarium solani species complex.

${ }^{c}$ Genera identified by ITS sequence and BLAST analysis on GenBank.
} 
leaves and galls (level 2, Table 1), discolored xylem and necrotic tissues were not found.

In the dead branches of specimen R10 and the main stem of Is2, galleries of ambrosia beetles were densely formed in the discolored xylem (Fig. 5A and B), whereas galleries were not found in specimens Is1, On1, and On2. Living ambrosia beetles were found in galleries formed in the xylem of specimens R10 and Is2. Beetles from R10 were identified as Euwallacea fornicatus and E. piceus, and those from Is2 were E. funereus (Fig. 6).
Under the light microscope, pale yellow to brown substances were observed in some vessels and axial parenchyma cells in the discolored xylem of specimens Is2, On1, On2, and R10, as in the case of the previous study (Kuroda et al. 2017). Fungal hyphae were observed in this discolored xylem area. Hyphae had penetrated into the lumen of vessels and wood fibers from ray tissue. In the tissue surrounding the beetle galleries of specimens Is 2 and R10, hyphae were abundant in ray tissues and axial parenchyma cells adjacent to the galleries (Fig. 5C).

Table 4. Fusarium isolates used and their allele types

\begin{tabular}{|c|c|c|c|c|c|c|}
\hline \multirow[b]{2}{*}{ Isolate } & \multirow[b]{2}{*}{ Host tree } & \multirow[b]{2}{*}{ Locality } & \multirow[b]{2}{*}{ Island } & \multicolumn{2}{|c|}{ Allele $^{\mathbf{a}}$} & \multirow[b]{2}{*}{ Genotype } \\
\hline & & & & rDNA-ITS & $E F-1 \alpha$ & \\
\hline On1-a1 & On1 & Onna-son & Okinawa Island & it-1 & ef-4 (LC490894) & $1-4$ \\
\hline R10-a12 & R10 & Univ. of the Ryukyus & Okinawa Island & it-1 & ef-5 (LC490895) & $1-5$ \\
\hline On2-b3 & On2 & Onna-son & Okinawa Island & it-1 & ef-3 (LC490893) & $1-3$ \\
\hline $\mathrm{P} 2-\mathrm{f} 11^{\mathrm{b}}$ & $\mathrm{P} 2$ & Peace Memorial Park & Okinawa Island & it-1 (LC198903) & ef-1 (LC198905) & $1-1$ \\
\hline On1-b9 & On1 & Onna-son & Okinawa Island & it-1 & ef-1 & $1-1$ \\
\hline On1-c1 & On1 & Onna-son & Okinawa Island & it-1 & ef-1 & $1-1$ \\
\hline On2-a6 & On2 & Onna-son & Okinawa Island & it-1 & ef-1 & $1-1$ \\
\hline R1-BC6 ${ }^{b}$ & $\mathrm{R} 1$ & Univ. of the Ryukyus & Okinawa Island & it-2 & ef-1 & $2-1$ \\
\hline On2-a4 & On2 & Onna-son & Okinawa Island & it-2 & ef-1 & $2-1$ \\
\hline On2-c2 & On2 & Onna-son & Okinawa Island & it-2 & ef-1 & $2-1$ \\
\hline On1-a3 & On1 & Onna-son & Okinawa Island & it-3 & ef-1 & $3-1$ \\
\hline Is $2-\mathrm{f} 2$ & Is 2 & Ibaruma & Ishigaki Island & it-1 & ef-2 (LC490892) & $1-2$ \\
\hline R10-a11 & $\mathrm{R} 10$ & Univ. of the Ryukyus & Okinawa Island & it-2 & ef-8 (LC490898) & $2-8$ \\
\hline Is $2-c 2$ & Is 2 & Ibaruma & Ishigaki Island & it-1 & ef-6 & $1-6$ \\
\hline Is $2-c 3$ & Is 2 & Ibaruma & Ishigaki Island & it-1 & ef-6 & $1-6$ \\
\hline Is2-g6 & Is 2 & Ibaruma & Ishigaki Island & it-1 & ef-6 & $1-6$ \\
\hline Is2-g8 & Is2 & Ibaruma & Ishigaki Island & it-1 & ef-6 & $1-6$ \\
\hline Is $2-\mathrm{f} 4$ & Is 2 & Ibaruma & Ishigaki Island & it-2 (LC476551) & ef-6 (LC490896) & $2-6$ \\
\hline Is $2-f 6$ & Is 2 & Ibaruma & Ishigaki Island & it-2 & ef- 6 & $2-6$ \\
\hline Is $2-g 2$ & Is2 & Ibaruma & Ishigaki Island & it-2 & ef-6 & $2-6$ \\
\hline Is $2-h 3$ & Is 2 & Ibaruma & Ishigaki Island & it-2 & ef-6 & $2-6$ \\
\hline On1-b1 & On1 & Onna-son & Okinawa Island & it-2 & ef-6 & $2-6$ \\
\hline Is1-b5 & Is 1 & Ibaruma & Ishigaki Island & it-2 & ef-7 (LC490897) & $2-7$ \\
\hline Is $2-\mathrm{g} 7$ & Is 2 & Ibaruma & Ishigaki Island & it-2 & ef-9 (LC490899) & $2-9$ \\
\hline Is $2-\mathrm{g} 9$ & Is2 & Ibaruma & Ishigaki Island & it-2 & ef -9 & $2-9$ \\
\hline Is $2-g 10$ & Is 2 & Ibaruma & Ishigaki Island & it -2 & ef-9 & $2-9$ \\
\hline On1-c5 & On1 & Onna-son & Okinawa Island & it-3 & ef-10 & $3-10$ \\
\hline On1-b12 & On1 & Onna-son & Okinawa Island & it-3 (LC476552) & ef-10 (LC490900) & $3-10$ \\
\hline Is 1-b1 & Is 1 & Ibaruma & Ishigaki Island & it-3 & ef-11 (LC490901) & $3-11$ \\
\hline Is $2-\mathrm{a} 2$ & Is 2 & Ibaruma & Ishigaki Island & it-3 & ef-11 & $3-11$ \\
\hline Is $2-\mathrm{b} 3$ & Is2 & Ibaruma & Ishigaki Island & it-3 & ef-11 & $3-11$ \\
\hline Is $2-g 11$ & Is2 & Ibaruma & Ishigaki Island & it-3 & ef-11 & $3-11$ \\
\hline On2-a1 & On2 & Onna-son & Okinawa Island & it-3 & ef-11 & $3-11$ \\
\hline Is2-g5 & Is2 & Ibaruma & Ishigaki Island & it-4 (LC476553) & ef-12 (LC490902) & $4-12$ \\
\hline Is $2-\mathrm{g} 3$ & Is 2 & Ibaruma & Ishigaki Island & it-4 & ef-12 & $4-12$ \\
\hline Is2-e1 & Is2 & Ibaruma & Ishigaki Island & it-4 & ef-12 & $4-12$ \\
\hline On1-a8 & On1 & Onna-son & Okinawa Island & it-1 & - & - \\
\hline On1-b2 & On1 & Onna-son & Okinawa Island & it-1 & - & - \\
\hline On1-c2 & On1 & Onna-son & Okinawa Island & it-1 & - & - \\
\hline On1-c3 & On1 & Onna-son & Okinawa Island & it- 1 & - & - \\
\hline On1-c4 & On1 & Onna-son & Okinawa Island & it-1 & - & - \\
\hline On1-c8 & On1 & Onna-son & Okinawa Island & it-1 & - & - \\
\hline On1-c9 & On1 & Onna-son & Okinawa Island & it-1 & - & - \\
\hline On1-c11 & On1 & Onna-son & Okinawa Island & it-1 & - & - \\
\hline On1-c13 & On1 & Onna-son & Okinawa Island & it-1 & - & - \\
\hline On1-c18 & On1 & Onna-son & Okinawa Island & it-1 & - & - \\
\hline On2-a6 & On2 & Onna-son & Okinawa Island & it-1 & - & - \\
\hline On2-b2 & On2 & Onna-son & Okinawa Island & it-1 & - & - \\
\hline On1-b5 & On1 & Onna-son & Okinawa Island & it-2 & - & - \\
\hline On1-b7 & On1 & Onna-son & Okinawa Island & it-2 & - & - \\
\hline On1-b8 & On1 & Onna-son & Okinawa Island & it-2 & - & - \\
\hline On1-b11 & On1 & Onna-son & Okinawa Island & it-2 & - & - \\
\hline
\end{tabular}

\footnotetext{
${ }^{a}$ Accession numbers in GenBank are shown in parentheses.

${ }^{b}$ Referred to Kuroda et al. (2017).
} 
Geographical distribution and identification of fungi belonging to the FSSC. Table 3 shows a list of fungi detected from all specimens from three sampling sites (Table 1; Fig. 3). Twenty-three isolates having the same nucleotide sequences of the rDNA-ITS gene that were assigned to the pathogenic isolate it- 1 of the FSSC were detected from specimens Is2, On1, On2, and R10. Thirty-three isolates having the same nucleotide sequences of the rDNA-ITS gene as it-2 were detected from all of the harvested trees. Isolates of it- 2 have rDNA-ITS genes with only one nucleotide substitution compared with those of it-1. Fungi grouped as it- 1 and it- 2 of the FSSC were distributed on both Ishigaki and Okinawa Islands.

DNA sequencing revealed four (it-1 to it-4) and 12 (ef-1 to ef-12) alleles at rDNA-ITS and $E F-1 \alpha$, respectively, among Fusarium isolates tested (Table 4). By combining these alleles at the two gene loci, the 36 Fusarium isolates were classified into 15 unique multilocus genotypes. These genotypes were designated using abbreviations of each contributing allele. For example, the isolate that shows it2 and ef- 1 alleles was designated as having a 2-1 genotype. A

Table 4. (Continued from previous page)

\begin{tabular}{|c|c|c|c|c|c|c|}
\hline \multirow[b]{2}{*}{ Isolate } & \multirow[b]{2}{*}{ Host tree } & \multirow[b]{2}{*}{ Locality } & \multirow[b]{2}{*}{ Island } & \multicolumn{2}{|c|}{ Allele ${ }^{\mathbf{a}}$} & \multirow[b]{2}{*}{ Genotype } \\
\hline & & & & rDNA-ITS & $E F-1 \alpha$ & \\
\hline On1-b13 & On1 & Onna-son & Okinawa Island & it-2 & - & - \\
\hline On1-b14 & On1 & Onna-son & Okinawa Island & it-2 & - & - \\
\hline On1-b15 & On1 & Onna-son & Okinawa Island & it-2 & - & - \\
\hline On1-b16 & On1 & Onna-son & Okinawa Island & it-2 & - & - \\
\hline On1-b20 & On1 & Onna-son & Okinawa Island & it-2 & - & - \\
\hline On1-b21 & On1 & Onna-son & Okinawa Island & it-2 & - & - \\
\hline On1-b22 & On1 & Onna-son & Okinawa Island & it-2 & - & - \\
\hline On1-b23 & On1 & Onna-son & Okinawa Island & it-2 & - & - \\
\hline On1-b24 & On1 & Onna-son & Okinawa Island & it-2 & - & - \\
\hline On1-b25 & On1 & Onna-son & Okinawa Island & it-2 & - & - \\
\hline On2-a3 & On2 & Onna-son & Okinawa Island & it-2 & - & - \\
\hline On2-a7 & On2 & Onna-son & Okinawa Island & it-2 & - & - \\
\hline On2-c3 & On2 & Onna-son & Okinawa Island & it-2 & - & - \\
\hline $\mathrm{R} 10-\mathrm{a} 1$ & $\mathrm{R} 10$ & Univ. of the Ryukyus & Okinawa Island & it-2 & - & - \\
\hline $\mathrm{R} 10-\mathrm{a} 2$ & $\mathrm{R} 10$ & Univ. of the Ryukyus & Okinawa Island & it-2 & - & - \\
\hline R10-a7 & $\mathrm{R} 10$ & Univ. of the Ryukyus & Okinawa Island & it-2 & - & - \\
\hline R10-a9 & $\mathrm{R} 10$ & Univ. of the Ryukyus & Okinawa Island & it-2 & - & - \\
\hline On1-a2 & On1 & Onna-son & Okinawa Island & it-3 & - & - \\
\hline On1-a4 & On1 & Onna-son & Okinawa Island & it-3 & - & - \\
\hline On1-a5 & On1 & Onna-son & Okinawa Island & it-3 & - & - \\
\hline On1-a6 & On1 & Onna-son & Okinawa Island & it-3 & - & - \\
\hline On1-a7 & On1 & Onna-son & Okinawa Island & it-3 & - & - \\
\hline On1-a10 & On1 & Onna-son & Okinawa Island & it-3 & - & - \\
\hline On1-a12 & On1 & Onna-son & Okinawa Island & it-3 & - & - \\
\hline On1-a13 & On1 & Onna-son & Okinawa Island & it-3 & - & - \\
\hline On1-a14 & On1 & Onna-son & Okinawa Island & it-3 & - & - \\
\hline On1-a15 & On1 & Onna-son & Okinawa Island & it-3 & - & - \\
\hline On1-a16 & On1 & Onna-son & Okinawa Island & it-3 & - & - \\
\hline On1-a17 & On1 & Onna-son & Okinawa Island & it-3 & - & - \\
\hline On $1-\mathrm{a} 20$ & On1 & Onna-son & Okinawa Island & it-3 & - & - \\
\hline On1-a21 & On1 & Onna-son & Okinawa Island & it-3 & - & - \\
\hline On1-a22 & On1 & Onna-son & Okinawa Island & it-3 & - & - \\
\hline On1-a23 & On1 & Onna-son & Okinawa Island & it-3 & - & - \\
\hline On1-a24 & On1 & Onna-son & Okinawa Island & it-3 & - & - \\
\hline On1-a25 & On1 & Onna-son & Okinawa Island & it-3 & - & - \\
\hline On1-a26 & On1 & Onna-son & Okinawa Island & it-3 & - & - \\
\hline On1-b10 & On1 & Onna-son & Okinawa Island & it-3 & - & - \\
\hline On1-c6 & On1 & Onna-son & Okinawa Island & it-3 & - & - \\
\hline On1-c7 & On1 & Onna-son & Okinawa Island & it-3 & - & - \\
\hline On1-c10 & On1 & Onna-son & Okinawa Island & it-3 & - & - \\
\hline On1-c12 & On1 & Onna-son & Okinawa Island & it-3 & _- & - \\
\hline On1-c14 & On1 & Onna-son & Okinawa Island & it -3 & - & - \\
\hline On1-c15 & On1 & Onna-son & Okinawa Island & it-3 & - & - \\
\hline On1-c16 & On1 & Onna-son & Okinawa Island & it-3 & - & - \\
\hline On1-c19 & On1 & Onna-son & Okinawa Island & it-3 & - & - \\
\hline On1-c20 & On1 & Onna-son & Okinawa Island & it-3 & - & - \\
\hline On2-a2 & On2 & Onna-son & Okinawa Island & it-3 & - & - \\
\hline Is2-e3 & Is2 & Ibaruma & Ishigaki Island & it-4 & - & - \\
\hline Is2-e6 & Is2 & Ibaruma & Ishigaki Island & it-4 & - & - \\
\hline Is2-e7 & Is 2 & Ibaruma & Ishigaki Island & it-4 & - & - \\
\hline Is2-g13 & Is 2 & Ibaruma & Ishigaki Island & it-4 & - & - \\
\hline Is2-g14 & Is 2 & Ibaruma & Ishigaki Island & it-4 & - & - \\
\hline Is2-g15 & Is 2 & Ibaruma & Ishigaki Island & it-4 & - & - \\
\hline Is2-g16 & Is 2 & Ibaruma & Ishigaki Island & it-4 & _- & - \\
\hline Is $2-\mathrm{h} 2$ & Is 2 & Ibaruma & Ishigaki Island & it-4 & - & - \\
\hline
\end{tabular}


comparison of the rDNA-ITS sequence data of the Fusarium isolates revealed new patterns for nucleotide sequences compared with it-1. Some isolates, which have nucleotide sequences with one nucleotide substitution, as in the case of it-2, were detected from all harvested trees except for R10 and were tentatively named it-3. Other isolates, which have nucleotide sequences with eight nucleotide substitutions, were detected only in Is 2 and were tentatively named it- 4 . The isolates of it-3 and it- 4 were first detected in the present investigation. Fungi grouped as it- 1 to it- 4 were predominantly isolated from various parts of declining E. variegata trees with discolored xylem in the stem or branches, whereas other fungi, such as Scedosporium spp. and Peniophora spp., were isolated only from necrotic tissue at a lower frequency (Table 3). In addition, these isolates grouped as it-1 to it-4 showed 12 types of sequence data of $E F-1 \alpha$ genes, and some isolates had the same nucleotide sequences of $E F-1 \alpha$ genes, even though those have different nucleotide sequences of rDNA-ITS genes.

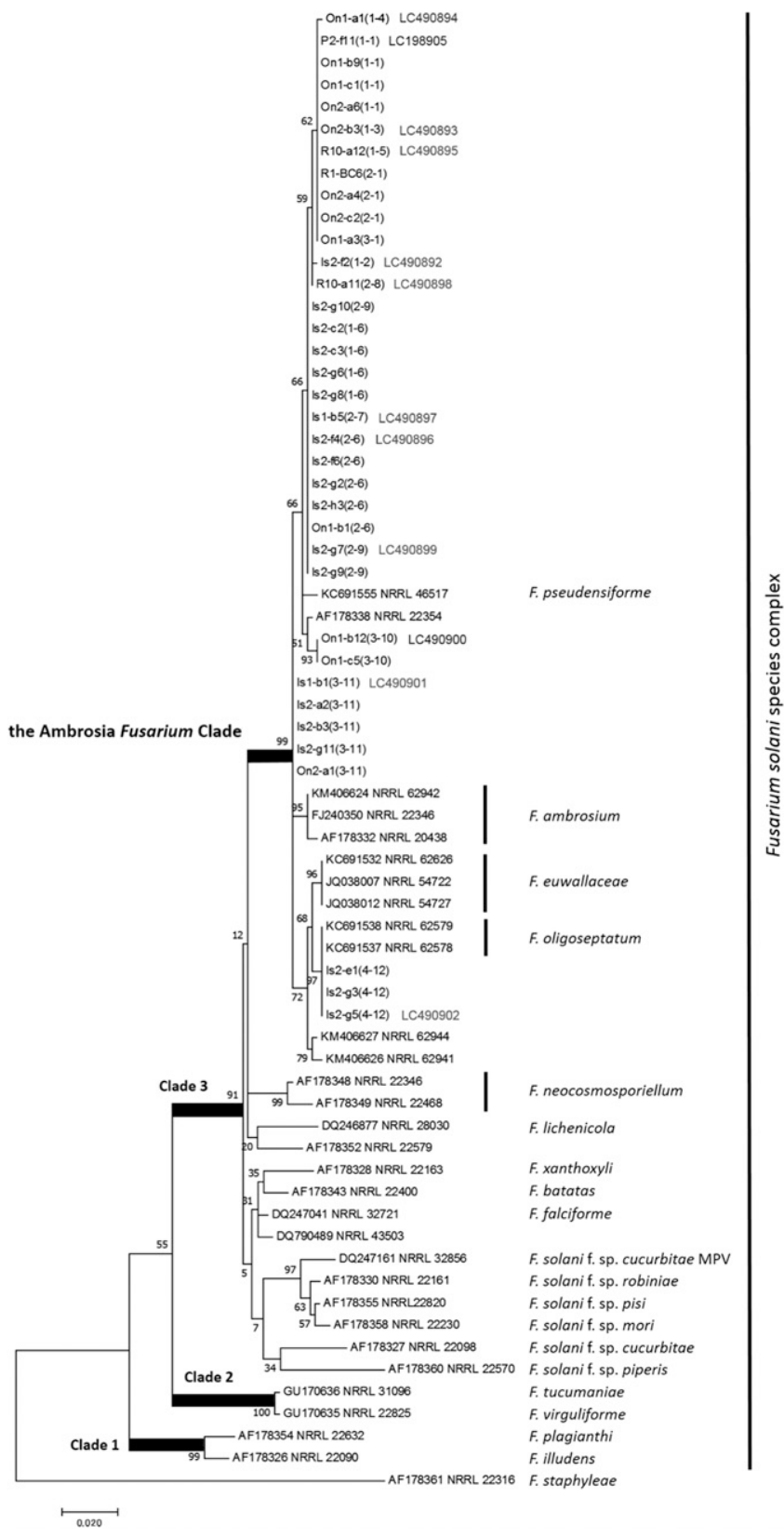

Fig. 7. Maximum likelihood phylogenetic tree based on $E F-1 \alpha$ nucleotide sequences. Numbers at nodes represent bootstrap support $>50 \%$ from 1,000 replicates. Three clades in the Fusarium solani species complex and the ambrosia Fusarium clade are indicated by bold internodes. Accession numbers and NRRL (the ARS Culture Collection) or FRC (Fusarium Research Center) numbers are shown. Isolates are denoted by the isolate name with the genotype in parentheses as shown in Table 4.
Nucleotide sequence analysis of the ITS and the $E F-1 \alpha$ indicated that it -2 , it -3 , and it -4 belong to clade 3 of the FSSC as defined by O'Donnell et al. (2008), which is the same as it-1 (Kuroda et al. 2017, P2-f11; Table 4). Figure 7 shows the phylogenetic tree inferred from the nucleotide sequences of the $E F-1 \alpha$ using 31 Fusarium isolates from GenBank and 36 representative Fusarium isolates that were detected at all sampling sites. Each isolate shows the isolate name with its genotype on the phylogenetic tree. Specifically, all of our isolates belong to the ambrosia Fusarium clade (AFC). Fungi isolated at a lower frequency were not identified because they were less likely to be pathogens.

Development of external symptoms after inoculation with two isolates of it-2. Representative characteristics of external symptoms are shown in Figures 8 and 9. All 48 seedlings inoculated with isolates of either R1-BC6 or Is2-f4 showed external symptoms. Twelve of these seedlings finally died, but some of the inoculated seedlings survived (Fig. 2). Leaf drooping was observed starting 3 or 4 days after inoculation in 58.3 and $66.7 \%$ of seedlings inoculated with isolates from Okinawa Island and Ishigaki Island, respectively (Fig. 2, open circle and double circle). Defoliation then occurred rapidly in 75 and $95.8 \%$ of the seedlings inoculated with each isolate within a few days of leaf drooping, or even without symptoms on leaves (Figs. 8B, 8C, and 9). Complete defoliation occurred on 50 and $58.3 \%$ of the seedlings inoculated with each isolate beginning 4 days after inoculation (Fig. 2, filled circle; Fig. 8D). Red to brown fluid began to exude from the lower stems of seedlings with the symptom of defoliation (Fig. 2, open triangle; Fig. 8E). Necrosis of the cortex and phloem with an odor occurred starting 21 days after inoculation (Fig. 2, filled rectangle). Symptoms did not develop synchronously among the fungus-inoculated seedlings. Similarly, death also occurred independently; for instance, five seedlings with R1-BC6 died between 8 and 35 days after inoculation, whereas seven seedlings with Is2-f4 died between days 14 and 49. Symptom development ceased in a few seedlings with partial defoliation, and one or two shoots sprouted at the inoculation sites (Fig. 9). Isolate Is2-f4 from Ishigaki Island demonstrated rapid symptom development compared with R1-BC6 from Okinawa Island. All control seedlings showed no external symptoms.

In the reisolation experiment, the two isolates either R1-BC6 or Is2-f4 of it- 2 were reisolated from tissues adjacent to the inoculation sites of fungus-inoculated seedlings. In contrast, fungi used for the inoculation experiment were not detected in any of the 12 control seedlings.

Development of internal symptoms after inoculation with two isolates of it-2. Internal symptoms observed in the tissue around the inoculation sites are shown in Figure 10. Xylem discoloration detectable with the naked eye became more widespread in the later period, especially 14 days after inoculation. In seedlings without external symptoms, xylem discoloration had not spread. In the completely defoliated seedlings, the area of xylem discoloration covered a large proportion of the stem's cross section. In dead specimens around 21 days after inoculation, the xylem was completely discolored and had been desiccated. In some inoculated seedlings, cambial activity continued partially as defoliation progressed. Tissues of control seedlings without wounds had no abnormalities, and those with just a wound had formed narrow dark-colored discoloration around the drilled wound.

Under a light microscope, pale yellow to brown substances were observed in parenchyma cells in the above-mentioned discolored xylem. The colored substances had plugged the lumen of some vessels (Fig. 11). Fungal hyphae were densely distributed in vessels and axial parenchyma cells around the inoculation sites. In all of the control seedlings, no hyphae were present in the stem tissues. In the controls with wounds, a small amount of a pale-brown substance had accumulated in some vessels just around the wound.

\section{Discussion}

In the present study, $25 \%$ of seedlings inoculated with isolates characterized as it-2 (R1-BC6 from Okinawa Island or Is2-f4 from Ishigaki Island) were killed after the development of symptoms, such 
as abnormal defoliation and necrosis of phloem with odor, similarly to naturally declining trees. Compared with the case of it-1 (P2-f11), which killed one-third of the inoculated seedlings (Kuroda et al. 2017), the mortality rate and internal and external symptoms caused by the inoculation of it- 2 isolates were the same. By the successful reisolation of it-2 FSSC fungi from dead seedlings, we judged that the two it-2 isolates belonging to the FSSC (R1-BC6 and Is2-f4) are pathogenic to E. variegata.

In the artificial inoculation with isolates of it-2, internal symptoms-(i) gray to brownish xylem discoloration associated with the stoppage of xylem sap movement and (ii) necrosis of cambium and phloem in the area of fungal distribution-were the same as those of naturally dying trees. They were also same as seedlings inoculated with an isolate of it-1 (Kuroda et al. 2017). Xylem discoloration is known to occur as a defense mechanism to protect trees from microbial invasion by secondary metabolites, and the discolored area is called "wound heartwood" or "pathological heartwood" (Hillis 1987). Water conduction stops in wound heartwood; therefore, the xylem sap flow decreases as the discolored xylem area enlarges in tree stems (Kuroda and Yamada 1996). The mechanism of tree wilt has been well explained in preceding reports on Japanese oak wilt caused by Raffaelea quercivora (Kuroda 2001) and fig canker caused by Ceratocystis ficicola (Kajii et al. 2013). During experiments in which fig seedlings were inoculated with pathogenic C. ficicola (Morita et al. 2016; Sumida et al. 2016) and Pittosporum tobira seedlings with pathogenic $F$. solani (Yamaoka et al. 2015), severe and wide discoloration occurred in the xylem, and the vessels became dysfunctional due to the production of secondary metabolites. Due to the similarities in the internal symptoms of these tree diseases, the decline and mortality of $E$. variegata trees infected with the FSSC will also be categorized as a wilt disease. The survival of inoculated seedlings was due to a small amount of water conduction maintained in the xylem that was newly formed by the partial survival of the cambium after infection. Although the cause of abnormal defoliation of $E$. variegata has been believed to be due to infestation by the gall wasp, $Q$. erythrinae, the present results and the preceding report by Kuroda et al. (2017) suggest the possibility that defoliation may be accelerated by the water deficit in upper tree bodies infected with pathogenic fungi.

The decline and mortality of $E$. variegata trees also occurred on Ishigaki Island, located $400 \mathrm{~km}$ south of Okinawa Island, with the same symptoms. From the fact that the nucleotide sequences of the ITS of 11 isolates obtained from Ishigaki Island were in accordance with the isolates of it- 1 and it-2 found on Okinawa Island (Kuroda et al. 2017), Erythrina decline is caused by the specific fungi of the FSSC widely including Ishigaki Island. Fungi belonging to it-1 and it- 2 were also widely distributed on Okinawa Island, judging from their detection in the Onna-son Village, located $70 \mathrm{~km}$ north of Peace Memorial Park. However, the history of the wide distribution of these fungi over hundreds of kilometers is unknown. The route of pathogen spread from dead trees to healthy trees is unknown.
F. solani f. sp. mori, a pathogen of Pittosporum tobira and a member of the FSSC, also has a wide distribution $\sim 1,650 \mathrm{~km}$ inside Japan (Masuya et al. 2012), and the distribution history is similarly unknown.

The route of pathogen spread at close range was hypothesized to be as follows. Fusarium spp. mainly inhabit soil, and the infection of adjacent trees occurs frequently via root contact underground (Aoki et al. 2014). The present and preceding investigations (Kuroda et al. 2017) found that adjacent Erythrina trees planted along roads often die off sequentially. This suggests that infection at close range occurs via soil and root contact; therefore, we are currently investigating the fungi inhabiting soil under declining trees. The process of disease spread in a wide region over the sea is still unknown. In Taiwan, located $\sim 320 \mathrm{~km}$ from Ishigaki Island, E. variegata is also severely declining, and infestation by the gall wasp $Q$. erythrinae was first reported in 2003 (Yang et al. 2004). In addition, we have information that Fusarium solani has been found in declining E. variegata trees there. The fungi are possibly the same or closely related to isolates of it-1 and it- 2 . We may need to consider some contribution of human activities for the long-distance spread of pathogens.

Naturally declining trees with thick trunks, commonly over $30 \mathrm{~cm}$ in diameter, demonstrate slower symptom development, and it takes more than several years from the decrease of leaves to phloem necrosis and complete death. If trees take many years from infection to mortality, the declining thick trees will have a long history after infection. In such cases, investigating infection routes and the contribution of vectors is difficult because we cannot obtain newly infected trees.

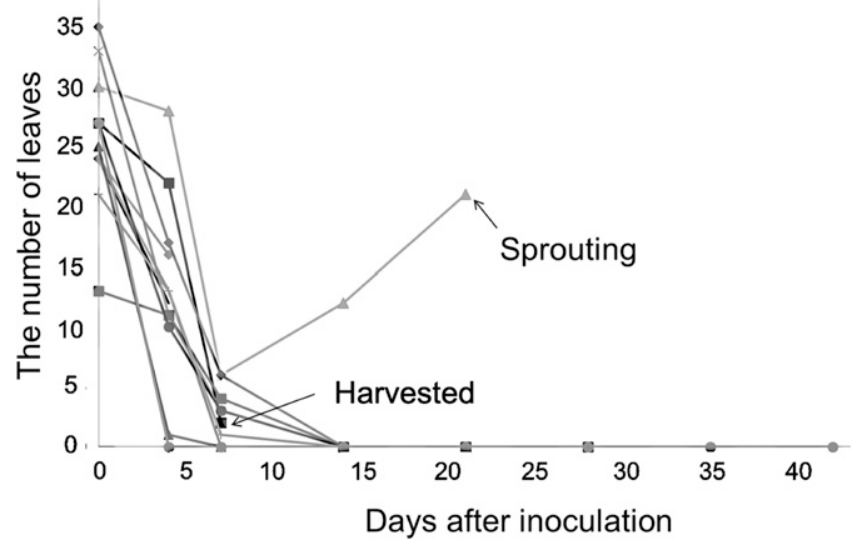

Fig. 9. Defoliation of Erythrina variegata seedlings inoculated with the it-2 isolate (Is2-f4). Each line shows the number of leaves of each specimen until harvesting.
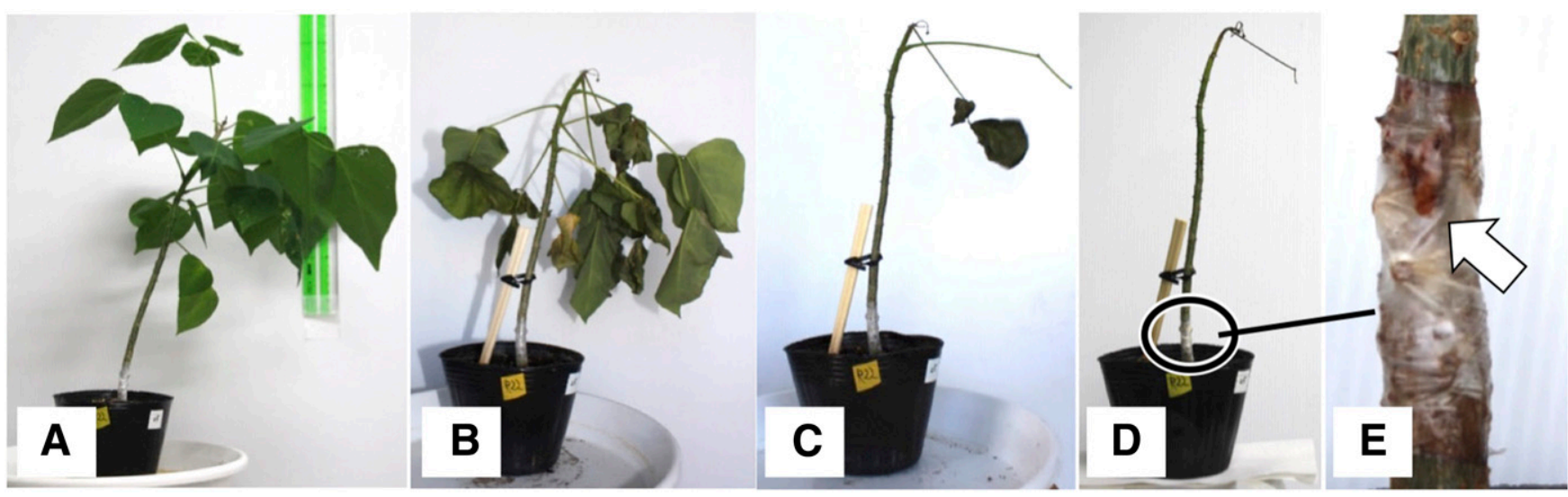

Fig. 8. External symptoms observed in Erythrina variegata seedlings inoculated with the it-2 isolate (R1-BC6): examples of specimen Ru-ino 8 (A to D) and Ru-ino 12 (E) are shown. A, Healthy seedling on the day of inoculation. B, Leaf drooping 3 days after the inoculation. C, Defoliation 4 days after inoculation. D, Death 7 days after inoculation. E, Fluid exudation (arrow) from the lower stem 4 days after inoculation. 
By phylogenetic analysis, all isolates that were grouped into it-1 to it-4 based on the analysis of ITS were revealed to be members of the AFC. AFC members are symbionts of ambrosia beetles (Kasson et al. 2013). F. pseudensiforme, known as a pathogen of Fusarium dieback of avocados (Eskalen et al. 2012; Kasson et al. 2013), is phylogenetically very close to some isolates from $E$. variegata, including the pathogenic ones, P2-f11, R1-BC6, and Is2-f4. Another two isolates (On1-b12 and On1-c5) that have the 3-10 genotype are very close to AF17338 NRRL 22354, which has not been named, in the phylogenetic tree. Three isolates (Is2-g5, Is2-g3, and Is2-e1) that have the 4-12 genotype might be $F$. oligoseptatum, known as a pathogen that causes the decline of Ailanthus altissima (tree of heaven) (Aoki et al. 2018). Two pathogenic FSSCs-F. euwallacea, which is another pathogen of avocados, and $F$. ambrosium, which is a pathogen of tea trees (O'Donnell et al. 2015) - are also close to some isolates detected in this study. Almost all isolates were genetically close to each other, even though they were distributed in different places of Ishigaki and Okinawa Islands. From the above-mentioned conditions of the phylogenetic data, it seems difficult to name the fungi pathogenic to $E$. variegata as a new species because there are a number of unknown fungi close to our isolates. Phylogenetic research should be continued so the pathogenic fungi can be named.

Among ambrosia beetles, the genus Euwallacea is known as a symbiont of Fusarium spp. in the AFC (Freeman et al. 2013; O'Donnell et al. 2015). We found Euwallacea fornicatus (the tea shot-hole borer), which is reportedly a symbiont of $F$. ambrosium and F. euwallacea, in declining E. variegata trees at the University of the Ryukyus. This species has a wide host range of more than 100 species of plants and trees, including avocado and tea in Asia (Eskalen et al. 2013; Freeman et al. 2013; O'Donnell et al. 2015; Ploetz et al. 2013) and E. variegata in China (Li et al. 2016). This ambrosia beetle is known as an insect pest of mango trees in Japan (Yamaguchi et al. 2006). Among other two beetle species, E. piceus is widely distributed in Oceania, Africa, and Asia (Wood and Bright 1992), and Erythrina subumbrans (December tree) is known as one of the host plants. This species was first discovered by us in living trees in Japan. The last one, E. funereus, is found in Oceania and Southeast Asia, and the hosts trees are Sterculia alata and Ficus infectoria (Beaver and Liu 2010). This species was also first described by us in Japan. Judging from the data of Euwallacea interjectus as a vector of the pathogen C. ficicola (Kajii et al. 2013; Morita et al. 2016; Sumida et al. 2016), detailed field research will be necessary to examine the relationship between ambrosia beetles and the distribution of pathogens of $E$. variegata trees.

In conclusion, the present study revealed that fungi belonging to it- 1 and it- 2 are pathogenic to E. variegata, categorized in the AFC of the FSSC, and are responsible for the mortality of E. variegata trees in a geographically wide area of Okinawa Prefecture, Japan. Besides pathogenic isolates of it-1 and it-2, such as P2-f11 (Kuroda et al.

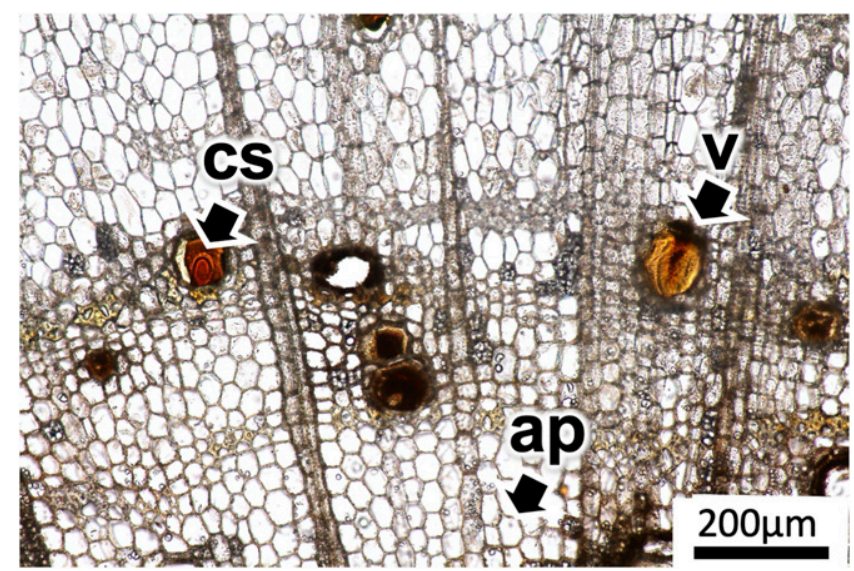

Fig. 11. Accumulation of pale yellow to brown substances (cs) observed in the vessels (v) and axial parenchyma cells (ap) as a defense reaction. Cross section of the specimen Ru-ino 12 without staining.

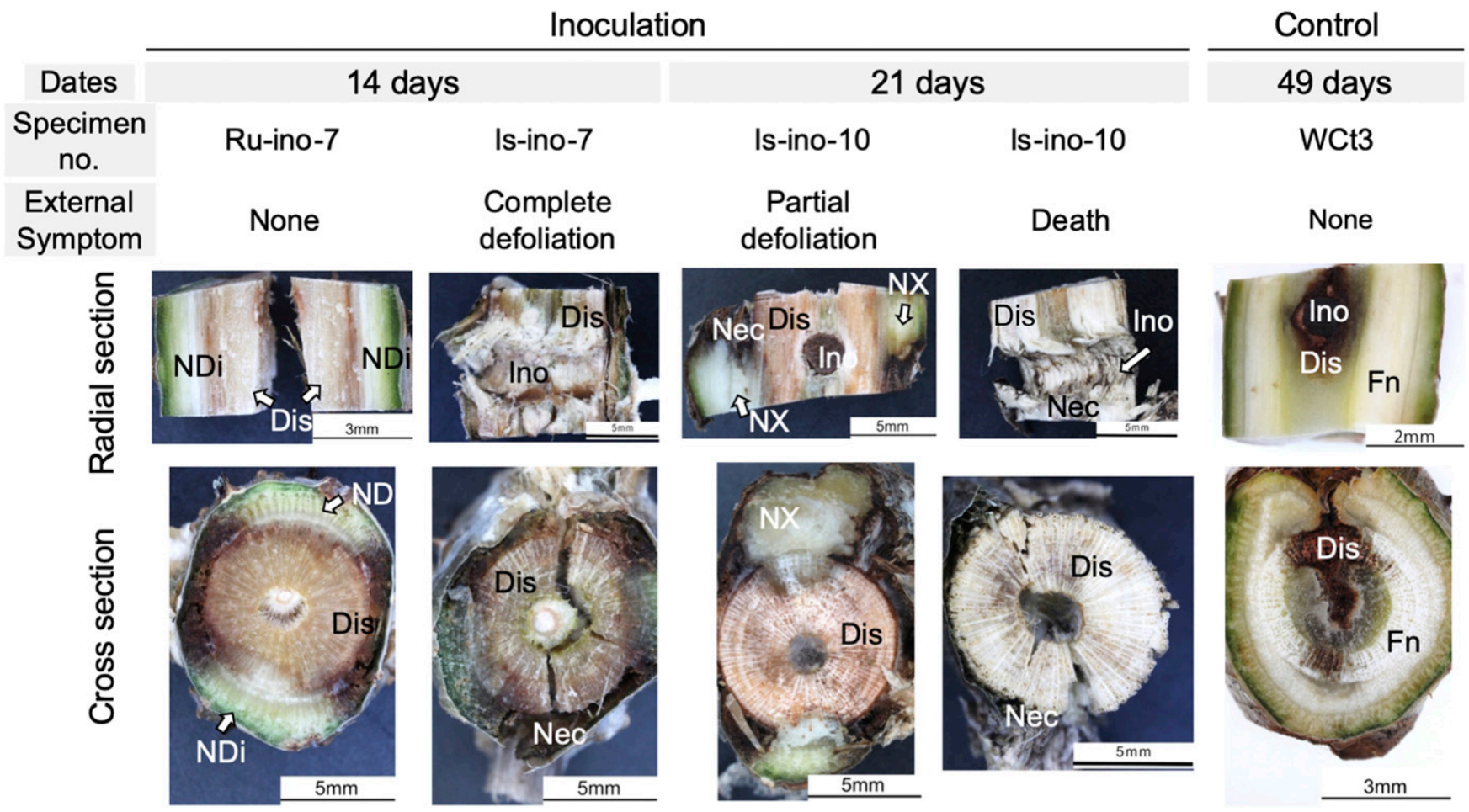

Fig. 10. Macroscopic view of internal symptoms observed on the cross and radial sections of seedlings inoculated with the it-2 isolates. No symptoms (14 days): discoloration progressed in the xylem, phloem, and cortex. Partial defoliation (21 days): wide discoloration in the xylem, but for the regeneration of cambium and additional xylem formation, water conduction was partly maintained. Complete defoliation and death (14 and 21 days): complete xylem discoloration and necrosis of the cambium. Control (49 days): no discoloration in the xylem but only around the inoculation sites. Dis = discolored xylem; $\mathrm{NDi}=$ non-discolored xylem; Ino = inoculation site; $\mathrm{NX}=$ newly formed xylem; Fn = functional $x y l e m ;$ and $\mathrm{Nec}=$ necrotic cambium and phloem . 
2017), Is2-f4, and R1-BC6, isolates genetically close to them were found and grouped as it-3 and it-4 in Okinawa Prefecture. Detailed research should be conducted on the pathogenicity and the phylogenetic relationship between them. Judging from data that $F$. solani was found in declining Erythrina spp. in Pakistan and India (Faizal et al. 2006; Javaid et al. 2005), genetically close species in the FSSC may be widely distributed in tropical and subtropical Asia and may be pathogenic to other Erythrina spp. or other tree species, such as tea or mango. Unfortunately, there is insufficient information on the FSSC found in Pakistan and India because these fungi were just optically identified without DNA analysis. We cannot tell whether their fungi are phylogenetically the same or close to the pathogenic isolates. Investigations on the distribution of the AFC species will be necessary across a wide area of tropical Asia, Hawaii, and other regions of Erythrina decline and mortality.

Two important subjects remain to be investigated. First, the effects of $Q$. erythrinae and the FSSC should be analyzed separately. Q. erythrinae is responsible for decreased flowering by gall formation, but the wasp cannot cause tree mortality. The effect of $Q$. erythrinae on the physiological condition of Erythrina trees is still unclear. One possibility is that the wasp infestation might add some stress to the host and promote the pathogen's activity. The second possibility is that infection with the pathogenic FSSC may decrease the protective reaction of hosts and facilitate the wasp infestation. The third is that the two organisms do not cooperate at all in the decline of $E$. variegata trees. Judging from the fact that $E$. variegata had been spontaneously dying in Okinawa Prefecture before the discovery of $Q$. erythrinae infestation in that area (Kameyama 2018), the pathogen seems to kill trees without the wasp's contribution. Further detailed investigations are necessary on the physiological aspects of host trees.

The second subject is how to control this wilt disease. As a protective procedure in Okinawa Prefecture, insecticide has been injected to kill the larvae of $Q$. erythrinae in galls. Although $Q$. erythrinae is not the cause of Erythrina mortality, Okinawa Prefecture is starting to biologically control $Q$. erythrinae with Eurytoma erythrinae, a wasp indigenous to Africa, following the strategy demonstrated in Hawaii (Bell et al. 2013). This method has not proved to be effective in preventing decline in Hawaii (Yalemar et al. 2009), and the induction of foreign species for pest control should be reconsidered because we cannot predict the impact of the induced organisms on domestic species. Based on the results of our investigations, we recommend fungicide injections to prevent the colonization of pathogenic fungi in the trunk. To keep E. variegata flowering and decrease mortality, pathogenic fungi should be controlled. Otherwise, planting Erythrina spp. that are native to Africa and known to be resistant to $Q$. erythrinae infestation (Messing et al. 2008) will be effective at maintaining flowering and as another procedure to prevent infection with the pathogenic Fusarium spp.

\section{Acknowledgments}

The authors are grateful to Takayuki Aoki (National Institute of Agrobiological Sciences, Genetic Resources Center) for his advice on the phylogenetic analysis of Fusarium spp. We also thank the Ryukyu Sankei Co., Ltd., for supplying plant materials for the inoculation experiment and a resident who permitted the sampling of trees in her garden on Ishigaki Island.

\section{Literature Cited}

Aoki, T., Kasson, M. T., Berger, M. C., Freeman, S., Geiser, D. M., and O'Donnell, K. 2018. Fusarium oligoseptatum sp. nov., a mycosymbiont of the ambrosia beetle Euwallacea validus in the Eastern U.S. and typification of F. ambrosium. Fungal Syst. Evol. 1:23-39.

Aoki, T., O'Donnell, K., and Geiser, D. M. 2014. Systematics of key phytopathogenic Fusarium species: Current status and future challenges. J. Gen. Plant Pathol. 80:189-201.

Beaver, R. A., and Liu, L. Y. 2010. An annotated synopsis of Taiwanese bark and ambrosia beetles, with new synonymy, new combinations and new records (Coleoptera: Curculionidae: Scolytinae). Zootaxa 2602:1-47.

Bell, R. C., Belmaker, A., Couch, C. S., Marchetto, K. M., Simonis, J. L., Thomas, R. Q., Sparks, J. P., Brown, J. M., Francisco, K. S., and Manuel, M. E. 2013. Effectiveness of Erythrina gall wasp biocontrol and implications for the recovery of threatened Wiliwili trees (Fabaceae: Erythrina sandwicensis). J. Torrey Bot. Soc. 140:215-224.
Costa, S. S., Matos, K. S., Tessmann, D. J., Seixas, C. D., and Pfenning, L. H. 2016. Fusarium paranaense sp. nov., a member of the Fusarium solani species complex causes root rot on soybean in Brazil. Fungal Biol. 120:51-60.

Eskalen, A., Gonzalez, A., Wang, D. H., Twizeyimana, M., Mayorquin, J. S., and Lynch, S. C. 2012. First report of a Fusarium sp. and its vector tea shot hole borer (Euwallacea fornicatus) causing Fusarium dieback on avocado in California. Plant Dis. 96:1070.

Eskalen, A., Stouthamer, R., Lynch, S. C., Rugman-Jones, P. F., Twizeyimana, M., Gonzalez, A., and Thibault, T. 2013. Host range of Fusarium dieback and its ambrosia beetle (Coleoptera: Scolytinae) vector in southern California. Plant Dis. 97:938-951.

Faizal, M. H., Anith, K. N., Prathapan, K. D., Stephen, R., and Faseela, K. M. 2006. Beetle-fungus association leads to the death of gall wasp infested Erhtyrina trees. Insect Environ. 12:117-118.

Feder, N., and O'Brien, T. P. 1968. Plant microtechnique: Some principles and new methods. Am. J. Bot. 55:123-142.

Freeman, S., Protasov, A., Sharon, M., Mohotti, K., Eliyahu, M., Okon-Levy, N., Maymon, M., and Mendel, Z. 2013. Obligate feed requirement of Fusarium sp. nov., an avocado wilting agent, by the ambrosia beetle Euwallacea aff. fornicata. Symbiosis 58:245-251.

Hillis, W. E. 1987. Page 268 in: Heartwood and Tree Exudates. Springer-Verlag, Berlin, Germany.

Javaid, A., Bajwa, R., and Javaid, A. 2005. Fusarium root and stem rot of Erythrina suberosa Roxb. in Pakistan. Pak. J. Phytopathol. 17:105-107.

Jukes, T. H., and Cantor, C. R. 1969. Evolution of protein molecules. Pages 21-132 in: Mammalian Protein Metabolism. H. M. Munro, ed. Academic Press, New York, NY.

Kajii, C., Morita, T., Kajimura, H., Jikumaru, S., Kuroda, K., and Yamaoka, Y. 2013. Xylem dysfunction in Ficus carica infected with wilt fungus Ceratocystis ficicola and the role of the vector beetle Euwallacea interjectus. IAWA J. 34:301-312.

Kameyama, N. 2018. Recent progress in the insects and pest control study for a prefectural flower of Okinawa, Erythrina variegata. Tree Forest Health 22: 78-79 (in Japanese).

Kasson, M. T., O’Donnell, K., Rooney, A. P., Sink, S., Ploetz, R. C., Ploetz, J. N., Konkol, J. L., Carrillo, D., Freeman, S., Mendel, Z., Smith, J. A., Black, A. W., Hulcr, J., Bateman, C., Stefkova, K., Campbell, P. R., Geering, A. D., Dann, E. K., Eskalen, A., Mohotti, K., Short, D. P., Aoki, T., Fenstermacher, K. A., Davis, D. D., and Geiser, D. M. 2013. An inordinate fondness for Fusarium: Phylogenetic diversity of fusaria cultivated by ambrosia beetles in the genus Euwallacea on avocado and other plant hosts. Fungal Genet. Biol. 56:147-157.

Kim, I. K., Delvare, G., and La Salle, J. 2004. A new species of Quadrastichus (Hymenoptera: Eulophidae): A gall-inducing pest on Erythrina (Fabaceae). J. Hymenopt. Res. 13:243-249.

Kumar, A., Lingadurai, S., Jain, A., and Barman, N. R. 2010. Erythrina variegata Linn: A review on morphology, phytochemistry, and pharmacological aspects. Pharmacogn. Rev. 4:147-152.

Kumar, S., Stecher, G., and Tamura, K. 2016. MEGA7: Molecular Evolutionary Genetics Analysis Version 7.0 for bigger datasets. Mol. Biol. Evol. 33: $1870-1874$.

Kuroda, K. 2001. Responses of Quercus sapwood to infection with the pathogenic fungus of a new wilt disease vectored by the ambrosia beetle Platypus quercivorus. J. Wood Sci. 47:425-429.

Kuroda, K., Chuma, I., Kihara, T., Murakami, T., Takashina, K., Hiraoka, D., and Kameyama, N. 2017. First report of Fusarium solani species complex as a causal agent of Erythrina variegata decline and death after gall formation by Quadrastichus erythrinae on Okinawa Island, Japan. J. Gen. Plant Pathol. 83: 344-357.

Kuroda, K., and Yamada, T. 1996. Discoloration of sapwood and blockage of xylem sap ascent in the trunks of wilting Quercus spp. following attack by Platypus quercivorus. J. Jpn. For. Soc. 78:84-88.

Li, Y., Gu, X., Kasson, M. T., Bateman, C. C., Guo, J., Huang, Y., Li, Q., Rabaglia, R. J., and Hulcr, J. 2016. Distribution, host records, and symbiotic fungi of Euwallacea fornicatus (Coleoptera: Curculionidae: Scolytinae) in China. Fla. Entomol. 99:801-804.

Lombard, L., van der Merwe, N. A., Groenewald, J. Z., and Crous, P. W. 2015. Generic concepts in Nectriaceae. Stud. Mycol. 80:189-245.

Masuya, H., Kajimura, H., Tomisawa, N., and Yamaoka, Y. 2012. Fungi associated with Scolytogenes birosimensis (Coleoptera: Curculionidae) infesting Pittosporum tobira. Environ. Entomol. 41:255-264.

Messing, R. H., Noser, S., and Hunkeler, J. 2008. Using host plant relationships to help determine origins of the invasive Erythrina gall wasp, Quadrastichus erythrinae Kim (Hymenoptera: Eulophidae). Biol. Invasions 11:2233-2241.

Morita, T., Jikumaru, S., and Kuroda, K. 2016. Disease development in Ficus carica plants after inoculation with Ceratocystisficicola. (1) Relationship between xylem dysfunction and wilt symptoms. Jpn. J. Phytopathol. 82: 301-309.

O'Donnell, K. 2000. Molecular phylogeny of the Nectria haematococca-Fusarium solani species complex. Mycologia 92:919-938.

O’Donnell, K., Sink, S., Libeskind-Hadas, R., Hulcr, J., Kasson, M. T., Ploetz, R. C., Konkol, J. L., Ploetz, J. N., Carrillo, D., Campbell, A., Duncan, R. E., Liyanage, P. N., Eskalen, A., Na, F., Geiser, D. M., Bateman, C., Freeman, 
S., Mendel, Z., Sharon, M., Aoki, T., Cosse, A. A., and Rooney, A. P. 2015. Discordant phylogenies suggest repeated host shifts in the FusariumEuwallacea ambrosia beetle mutualism. Fungal Genet. Biol. 82:277-290.

O'Donnell, K., Sutton, D. A., Fothergill, A., McCarthy, D., Rinaldi, M. G., Brandt, M. E., Zhang, N., and Geiser, D. M. 2008. Molecular phylogenetic diversity, multilocus haplotype nomenclature, and in vitro antifungal resistance within the Fusarium solani species complex. J. Clin. Microbiol. 46:2477-2490.

Ploetz, R. C., Hulcr, J., Wingfield, M. J., and De Beer, Z. W. 2013. Destructive tree diseases associated with ambrosia and bark beetles, black swan events in tree pathology? Plant Dis. 97:856-872.

Reimar, N. J. 2008. Field release of Eurytoma sp. (Hymenoptera: Eurytomidae), for biological control of the Erythrina gall wasp, Quadrastichus erythrinae Kim (Hymenoptera: Eulohidae). Page 8 in: Hawaii. Final Environmental Assessment by Plant Pest Control Branch Hawaii Department of Agriculture, Honolulu, HI.

Rubinoff, D., Holland, B. S., Shibata, A., Messing, R. H., and Wright, M. G. 2010. Rapid invasion despite lack of genetic variation in the Erythrina gall wasp (Quadrastichus erythrinae Kim). Pac. Sci. 64:23-31.

Sumida, S., Kajii, C., Morita, T., and Kuroda, K. 2016. Disease development in Ficus carica seedlings after inoculation with Ceratocystis ficicola. (2) Microscopic analysis of the host-pathogen interaction and internal symptoms. Jpn. J. Phytopathol. 82:310-317.

Uechi, N., Uesato, T., and Yukawa, J. 2007. Detection of an invasive gall-inducing pest, Quadrastichus erythrinae (Hymenoptera: Eulophidae), causing damage to Erythrina variegata L. (Fabaceae) in Okinawa Prefecture, Japan. Entomol. Sci. 10:209-212.
White, T. J., Bruns, T., Lee, S., and Taylor, J. 1990. Amplification and direct sequencing of fungal ribosomal RNA genes for phylogenetics. Pages 315-322 in: PCR Protocols: A Guide to Methods and Applications. M. A Innis, D. H. Gelfand, J. J. Sninsky, and T. J. White, eds. Academic Press, San Diego, CA.

Wood, S. L., and Bright, D. E. 1992. A catalog of Scolytidae and Platypodidae (Coleoptera), Part 2: Taxonomic index. Volume A. Gt. Basin Nat. Mem. 13: $1-833$

Yalemar, J., Nagamine, W., Ramadan, M., and Bautista, R. 2009. Managing the Erythrina gall wasp problem in Hawaii by classical biological control. Page 27 in: Presentation of State of Hawaii Department of Agriculture, Honolulu.

Yamaguchi, T., Iwamoto, J., Goto, H., Nojima, H., Omatu, N., Torigoe, H., Yasuda, K., Setokuchi, O., and Hayashikawa, S. 2006. Insect pests of the mango plant, Mangifera indica, on the Amami islands, Japan. Kyushu Pl. Prot. Res. 52:60-65 (in Japanese with English abstract).

Yamaoka, Y., Kuroki, D., Matsutani, K., Aoyama, T., Masuya, H., and Kajimura, H. 2015. Pathogenicity of Fusarium solani associated with a bark beetle, Scolytogenes birosimensis, to Pittosporum tobira. J. For. Res. 20:514-521.

Yang, M., Tung, G., Salle, J. L., and We, M. 2004. Outbreak of Erythrina gall wasp (Hymenoptera: Eulophidae) on Erythrina spp. (Fabaceae) in Taiwan. Plant Prot. Bull. 46:391-396.

Zhang, N., O'Donnell, K., Sutton, D. A., Nalim, F. A., Summerbell, R. C., Padhye, A. A., and Geiser, D. M. 2006. Members of the Fusarium solani species complex that cause infections in both humans and plants are common in the environment. J. Clin. Microbiol. 44:2186-2190. 